\title{
Publisher Correction: Short-term air pollution, cognitive performance and nonsteroidal anti-inflammatory drug use in the Veterans Affairs Normative Aging Study
}

Xu Gao (D), Brent Coull, Xihong Lin, Pantel Vokonas, Avron Spiro 3rdiD, Lifang Hou, Joel Schwartz and Andrea A. Baccarelli iD

Correction to: Nature Aging https://doi.org/10.1038/s43587-021-00060-4, published online 3 May 2021.

In the version of this Letter originally published, in Table 1 , the value ' $0.414(0.116)$ ' was incorrect; it should have been ' $-0.414(0.116)$ '. All versions of the Letter have been amended.

Published online: 19 May 2021

https://doi.org/10.1038/s43587-021-00075-X

๑) Springer Nature America, Inc. 2021 